\title{
Phronesis, Virtues and the Developmental Science of Character
}

\author{
Commentary on Darnell, Gulliford, Kristjánsson, and Paris
}

Daniel Lapsley

University of Notre Dame, Notre Dame, IN, USA

\author{
Keywords \\ Phronesis · Character · Virtues
}

One of the striking trends over the last decade has been the increasing collaboration between empirical philosophers and psychologists across a wide range of topics, particularly with respect to character, virtues and other problems in moral psychology (e.g., Annas, Narvaez \& Snow, 2016; Sinnot-Armstrong \& Miller, 2017). This collaboration has been likened to good neighbors repairing a common wall at "spring mending time" (Lapsley, 2016, invoking Robert Frost's iconic poem "The Mending Wall"). As issues are passed like boulders one to the other from each side of the disciplinary divide, there are occasions for mutual correction, conversation and encouragement, but such collaboration does not mean giving up the relative autonomy of the two disciplines. As Tiberius (2015, p. 22) put it, philosophers and psychologists "can learn from each other without doing each other's jobs."

This is worth keeping in mind because there was a time when developmental psychologists ceded to philosophers the job of defining the domain of interest before they took up the empirical study of moral development. There is no particular objection to looking for guidance wherever it is most usefully found, of course, so long as the naturalizing tendencies sweeping through ethics is not a temptation to mistake philosophical concepts for empirical ones and so long as the theoretical ambitions of developmental (and psychological) science are not sent chasing after philosophical problems for which empirical data are not decisive or informative.

Admittedly, it is not always very clear where to mark the boundary; and whether collaboration proves useful is often known only in hindsight as one surveys and reconstructs the history of a research program. For this reason, Lakatos (1978) cautioned that new research programs should be treated leniently until there is a decent

\begin{tabular}{llll}
\hline KARGER & & Daniel Lapsley \\
E-Mail karger@karger.com & & Department of Psychology, 390 Corbett Family Hall \\
www.karger.com/hde & & University of Notre Dame \\
& Notre Dame, IN 46556 (USA) & E-Mail danlapsley@ nd.edu
\end{tabular}


track record to appraise growth in knowledge when compared against rival views. But it is a good strategic bet to look for progress where empirically responsible moral philosophy meets philosophically responsible moral psychology (Lapsley, 2016).

There are, in fact, promising examples of useful collaboration at the mending wall. For example, there are attempts to link psychological and philosophical views on character and virtue (Reilly \& Narvaez, 2018). Wright, Warren and Snow (forthcoming) base their understanding of virtue and how to measure it by appeal to whole trait theory in personality psychology (Fleeson \& Jayawickreme, 2015; Jayawickreme, Zachary \& Fleeson, 2019). Whole trait theory attempts to integrate trait and social cognitive approaches to personality, and it makes a claim for understanding neoAristotelian conceptions of virtue (Jayawickreme \& Fleeson, 2017). The challenge of situationism has focused the attention of social-personality psychologists and empirical philosophers alike (e.g., Doris, Stich, Phillips \& Walmsley, 2017; Fairweather \& Alfano, 2013; Fleeson, Furr, Jayawickreme, Meindl \& Helzer, 2014). Indeed, what philosophers make of cross-situational consistency of global character traits often hinges on how they read the research literatures of social, cognitive and personality psychology (Alfano, 2011; Doris, 2002; Miller, 2014; Russell, 2011).

There is also searching philosophical criticism of character strengths and of positive psychology more generally (Kristjánsson, 2013; Miller, 2019). Moreover, the appeal of Aristotle's Nichomachean Ethics has animated the conceptualization and practice of character education (e.g., Arthur, Kristjánsson, Harrison, Sanderse \& Wright, 2017; Kristjánsson, 2015). It also inspires current work on purpose, thriving, the conditions of flourishing and eudaimonia as a motivational and generative force in the human lifespan (e.g., Bauer, McAdams \& Pals, 2008; Fowers, 2012; Snow, 2015).

\section{The Phronesis Model}

In this context, consider the target article by Darnell, Gulliford, Kristjánsson and Paris (this issue). These authors extend the reach of Aristotle to address what they call the "gappiness" problem in moral development, which is the gap between moral knowledge and moral action. There is a difference, of course, between knowing the right thing to do and then doing it. According to Darnell and colleagues, moral development theory is inadequate for explaining gappiness to the extent it relies upon single component explanations, say, in terms of moral emotions (sympathy/empathy) or moral identity. Moreover, and more to the point, developmental models of morality also lack an Aristotelian account of phronesis. On the authors' account, phronesis is a multicomponent construct with multiple functions, and so brings more resources to bear on gappiness.

One function, for example, is constitutive. The constitutive function allows its possessor to gauge the salient features of situations from an ethical perspective. Phronesis also integrates components of the good life particularly in situations when the demands of virtue(s) seem to conflict. So it has an integrative function as well. Moreover, phronesis also requires some conception of eudaimonia, some conception of the good life to serve as a blueprint that permits the agent-possessor to adjust or construct his or her moral identity. It is this eudaimonic blueprint that adds motivational force to moral identity. Phronesis also contributes to emotional regulation by aligning emotions with construal of a given situation. As the authors put it, emotion 
regulation involves “... the infusion of emotion with reason, which calibrates the emotion in line with the morally and rationally warranted medial state of feeling, and the subsequent harmony between the two." Presumably the phronetic calibration of emotion-reason provides action guidance to moral behavior.

The authors propose, then, a four-component model of phronesis. The first component is the constitutive function of phronesis; it is the ability to notice that a situation is ethically relevant to require the activation of one or more virtues. The second component is the integrative function of phronesis; it involves weighing and adjusting the priority of virtues, particularly when situations are complex, and several are implicated. The third component of phronesis includes the life blueprint that gives shape to moral identity, while the fourth component involves the fine-tuning of emotions by reason.

The first three components of phronesis are said to bear some resemblance to the first three components of the better known four-component neo-Kohlbergian model of morality (e.g., Narvaez \& Rest, 1995; Rest, Narvaez, Bebeau \& Thoma, 1999). The differences are traced mostly to the fact that the phronetic model concerns virtues and aretaic considerations while the neo-Kohlbergian model concerns reasons, judgments and deontological considerations and so are like mirror images across the mending wall. The two models diverge more clearly at the fourth component. In the neo-Kohlbergian model the fourth component refers to the personological features (e.g., now likened to "performance virtues") that allow one to effectively implement a motivated and well-considered moral judgment. In contrast, the phronetic model has little need for performance virtues but requires instead an infusion of emotion with reason as the fourth component.

This brief summation is perhaps enough to motivate a commentary on the phronesis project undertaken by Darnell and colleagues. The target article does take up a number of other issues that will be of scarce interest to developmental psychology, such as locating phronesis within Aristotle's division of the soul, how it plays to the unity-of-virtues issue, how it relates to natural virtues, to cleverness, techne, sophia and the doctrine of the mean, among other topics. These issues can be safely left to philosophers to sort out. Of greater interest is the claim that phronesis is a distinctive psychological construct that has components that can be assessed with a measure. The authors concede that a developmental account of phronesis is currently unavailing or "murky," and educational implications are similarly unclear, other than to encourage students to read Aristotle's ethics and study literature. Yet these matters do count in the general appraisal of the challenges facing the phronetic model.

\section{Five Challenges}

In this section I press five general challenges for the phronesis model. First, I take up the issue of whether phronesis is a psychological construct in the first place or whether its functions are better understood in terms of other psychological theories. Second, the lack of a plausible developmental theory will raise the bar for many readers of this journal, particularly in light of very recent developmental accounts of character that find little reason to pay homage to Aristotle (e.g., Nucci, 2017, 2018). Third, I raise the concern that the present model trades on a distinction between emotion and cognition that is not countenanced by the literature and, indeed, falls prey to a discredited "pyramidal model" of the mind. Fourth, I revisit moral identity as one of 
the "single component" models noted in the target article and make a few clarifying observations about it. Finally, and as a conclusion, I suggest alternative philosophical approaches to phronesis and virtues that promise a tighter connection to psychological empirical traditions than does the present phronetic model and hence are more promising for dialogue across the mending wall of moral psychology.

\section{Phronesis as a Psychological Construct}

There is no question that phronesis does heavy lifting in virtue ethics. It is also true that there is no univocal understanding of what it is and how it works (Dunne, 1992; Russell, 2011). That phronesis is controversial and presents interpretive difficulty is acknowledged by Darnell and colleagues, but controversy is not my main concern. Rather, it is the notion that a philosophically disputed concept freighted with controversy could be imported so directly into psychology without translation. Phronesis is either not a psychological construct, or else it is one better accounted for by developmental constructs with a far better theoretical and empirical provenance.

Consider various features of phronesis. It is an intellectual virtue, a deliberative excellence that bespeaks practical wisdom. It allows its bearer to see clearly, to interpret situations, discern key features, generate salient reasons. It involves emotion regulation and issues context-sensitive decisions. Phronesis is also described as a metavirtue in the sense that it rides herd on subordinate virtues. It adjudicates conflict among virtues when several are summoned. Given the complexity of its operations, phronesis is necessarily a later developmental achievement, although the course of development is not well understood.

Yet, the psychological literature has long understood these central features of phronesis without instruction in Aristotle's ethics. Schema theory (in its various forms) has long framed contemporary understanding of memory, inference, social perception, decision-making, self-regulation, social information-processing and problem-solving (Higgins, Herman \& Zanna, 1981; Marshall, 1995). The perceptual sensitivity and discriminative facility credited to phronesis are a well-attested accomplishment of socialcognitive mechanisms (Mischel, 2004; Reilly \& Narvaez, 2018). These mechanisms orient attentional and encoding processes, influence how things are represented, interpreted and remembered. Social cognition generates attributions and underwrites the social inferences that are drawn (Fiske \& Taylor, 2013). It is curious, and certainly a missed opportunity, why the interdisciplinary conversation concerning the psychological specification of practical wisdom does not start right here with this formidable literature; or what is to be gained by swapping it out in favor of Aristotle's conception of phronesis? It is also difficult to know what is left for phronesis to do if it is asserted to be something other than what is accomplished by social cognitive mechanisms.

One possible objection is that the social cognitive functions I have described are not the work of virtue. In other words, phronesis, as a metavirtue, summons, manages and deploys virtues, not social cognitive constructs. But this gets the interdisciplinary conversation the wrong way round. It is readily conceded that the notion of practical wisdom has important work to do within virtue ethics, but it cannot be used like a wand to wave away entire psychological literatures as if they have no relevance for understanding the functions claimed for phronesis. One might ask, for example, what sort of things are virtues? Virtues require an empirical grounding and psycho- 
logical specification, and if the point of interdisciplinary conversation is to figure this out, then cognitive and social cognitive theory will have to matter. For phronesis to be treated seriously as a psychological construct, it will need to show that what it explains (and how it does so) has advantages over extant psychological theory. In the absence of such an argument, the insistence on phronesis will seem like a special plea for psychologists to use the Aristotelian lexicon.

It might be rejoined that the componential phronetic model is more than just the social cognitive "constitutive" or "integrative" functions, and that the very point of the target article is to show that it has comparative advantages over the four-component neo-Kohlbergian model of morality. I will return presently to the analysis of the crucial fourth component of phronesis because I do not think it provides the unequivocal advantage that is claimed for it. But more generally, I think the comparison of phronesis with the four-component model is misdirected. A more apt comparison would be to social cognitive theories of personality that already address the components of the phronetic model (e.g., Cantor, 1990) or else explicitly take up the issue of dispositional variability across situations, i.e., the gappiness problem (Cantor \& Kihlstrom, 1981; Cervone \& Shoda, 1999).

For example, Cantor (1990) describes the cognitive carriers of dispositions in terms of schemas, life tasks and strategies. Social cognitive schemas (as noted above) channel social perception, guide appraisal of social situations, access task-relevant memories and calibrate appropriate affective responses. Life tasks are social cognitive representations for life strivings, something the phronetic model understands as blueprints. Strategies are procedure blueprints (if you will) for implementing them. Unless the phronetic model is a social cognitive theory of practical wisdom, there is not much left for it to do.

Social cognitive approaches to personality also take up directly the "gappiness" problem, or what Mischel (2004) has called the "personality paradox," i.e., strong intuitions that personality is stable and invariant collide with empirical evidence that it is otherwise. The gappiness problem addressed in the target article is simply a special case of this personality paradox. But Mischel (2004) describes two types of personsituation consistency. Type 1 consistency concerns broad-brand individual differences on ratings of trait adjectives aggregated across situations. This strand of personality trait psychology has preoccupied disputants to the situationism debate; and it tends to favor a dispositional core and holds out for person-situation consistency typical of (what are termed) global traits.

In contrast, type 2 consistency looks for distinctive and stable patterns of intraindividual consistency not by appealing to interindividual differences in ratings on global trait adjectives derived from the lexicon, but in terms of social cognitive within-person variables that are implicated in social, cognitive, motivational and affective processes. These variables underwrite the ability of individuals to interpret the meaning of situations in characteristic ways and to motivate behavior accordingly. Put differently, a stable "behavioral signature" across situations is expected only when situations are interpreted to have the same psychological meaning for the individual. As Mischel (2004, p. 4) put it:

The focus has shifted away from broad situation-free trait descriptors with adjectives (e.g., conscientious, sociable) to more situation-qualified characterizations of persons in context, making dispositions situationally hedged, conditional and interactive with situations in which they were expressed. 
Mischel and others have proposed the cognitive affective processing system (CAPS) as a conceptual framework to account for distinctive patterns of behavior characteristic of individuals and to predict the two types of person-situation consistency. CAPS is a "componential" model, too. It describes personality as a system that contains mental representations, the activation of which underwrites dispositional coherence. These representations "... consist of diverse cognitive-affective units or CAUs, which includes the person's construal and representations of the self, people and situations, enduring goals, expectations-beliefs and feeling states, as well as memories of people and past events" (Mischel, 2004, p.11), and for a given individual some of these representations are highly accessible, readily primed and on call while other representations are not.

Another telling competitor to phronesis is the knowledge-and-appraisal personality architecture (KAPA) model (Cervone, 2004, 2005; Cervone \& Little, 2015). The KAPA model "is designed to characterize psychological systems that underlie crosssituational coherence and consistency in experience and action" (Cervone \& Tripathi, 2009, p. 35). Knowledge consists of enduring mental representations about persons and one's social world, including knowledge of self or self-schemas; appraisals refer to dynamic processes of meaning construction that occur within a given encounter, including subjective beliefs about social situations and the relevance of personal attributes to them. On this account, individuals "critically appraise the relevance of circumstances to their well-being, their capacity to cope with challenges in the environment, and the social and moral appropriateness of alternative courses of action" (Cervone \& Tripathi, 2009, p. 36). The promise of the KAPA model has been empirically documented with ideographically tailored assessments of self-schemas and situational beliefs in the prediction of cross-situational consistency (e.g., Caldwell, Cervone \& Rubin, 2008; Scott \& Cervone, 2016).

These social cognitive models (Cantor, CAPS, KAPA) understand personality in terms of complex systems of operations, functions and processes that seem more than capable of addressing gappiness, personality invariance and cross-situational variability of behavior. Moreover, these models insist not on consistency but on coherence of personality identified as stable but dynamic behavioral signatures at the crossroads of person $\times$ context interactions. These are the proper competitor models for phronesis and a good place to start if the goal is to understand Aristotle's practical wisdom as a psychological construct.

\section{Phronesis and Developmental Science}

One advantage of a social-cognitive starting point is its promise of deep integration with developmental models of personality and character (Lapsley \& Hill, 2009; Lapsley \& Narvaez, 2004) and with developmental contextualism more generally (Shoda \& Mischel, 2000). Both social cognitive and developmental system approaches seek to understand intraindividual change and variability, are suspicious of typologies and traits, hold out for coherence rather than consistency as behavioral features of moral character and draw attention to dynamic qualities of person $\times$ context interactions for any suitable understanding of how real lives are lived. Indeed, it is striking how much of the philosophical conversation about character has been taking place with social and personality psychology but comparatively little with developmental 
science. Two recent developmental accounts of character promise to shift the conversation.

Nucci $(2017,2018)$ argues, for example, that character is best described not by the language of virtues or traits but in terms of an overall self-system that includes (a) an overall sense of personal moral agency, (b) a unique personal (moral) identity and (c) a character system. The character system has several facets. It includes basic moral cognition, other-regarding social-emotional skills, self-regarding executive control of emotions and desires, and discourse skills that underwrite a capacity for critical engagement with one's social context. The character system is held to be in dynamic interaction with other aspects of the self-system and with context, which accounts for growth in character.

Lerner (2018) articulates a four-facet person-context relational view of character that is influenced by the relational developmental system metatheory (Overton, 2015). On this account character virtue development includes (a) mutuality (mutually beneficial relations between person and context), (b) coherence (which is likened to Aristotle's phronesis), (c) specificity (specific character virtues develop in specific contexts of mutually beneficial relations) and (d) which are best charted by means of ideographic methods. A comparison of the two models is instructive. Both view character as complex developmental systems marked by reciprocal, dynamic person-context relations. Both reject concepts common to the character tradition. For example, Nucci's model has little use for traits or virtues while Lerner's is hostile to traits, typologies, characteristic adaptations and variable-centered analyses, although at the same time Lerner's model retains the language of character virtue as a relational concept (rather than as a quality that adheres to persons).

One does not have to agree with every detail of the two models (and the models are not in complete agreement) to see that the challenge they pose to the character psychology presumed by the phronetic model is significant (Lerner's nod to phronesis notwithstanding). The developmental models force a reconceptualization of the central core units of personality and about what it means for character tendencies to cohere. The relational developmental system framework endorsed by both Nucci and Lerner will raise questions for the phronetic model about how to understand the development of moral agency, how to relate moral agency and character to the selfsystem and how to render a developmentally grounded account of how character (and its components) dynamically interpenetrate within changing contexts. But the two developmental models also offer a way forward. Both suggest that research on the development of character will require ideographic methods, particularly those that focus on narrative. The developmental grounding of phronesis might well be investigated using the panoply of narrative methodologies.

On this note I will make four additional observations. First, insofar as a developmental framework presupposes change, it is not driven to distraction by the situationism challenge nor is it motivated to defend a certain vision of virtue that requires cross-situational consistency; nor is it much interested in constructing psychological models to vindicate such views. A developmental psychology of phronesis will get off on the wrong foot if this is the starting point. This means that interdisciplinary conversation with developmental science will have a different tenor than what happens now with social and personality trait psychology.

Second, in his critique of consistency as a mark of character, Nucci (2017, p. 12) remarked that "... attempts to impose an impossible level of consistency ... assume a 
decontextualized psychological system that has little to do with an actual human being." Although Darnell and colleagues do not seem particularly committed to consistency and are open to coherence arguments, it does strike me that orienting a character psychology towards what is possible for the paragon of ideal virtue, the phronimos so crucial to Aristotelian virtue ethics, is to posit just such a decontextualized exemplar that has little to do with an actual human being. Although appeals to what the fully virtuous agent would do is invoked to show how virtue ethics can issue action-guiding prescriptive judgments (e.g., Hursthouse, 1999), it cannot do much work on the empirical side of the mending wall where it fails the test of psychological realism. Developmental science has some experience with such idealized abstractions, such as Kohlberg's rational moral agent or Piaget's epistemic subject, and so there will be doubts about the value of fully virtuous agents and phronimos in guiding an empirical research agenda.

Third, there are developmental accounts of rationality that could serve as a useful point of reference for discerning the developmental trajectory of phronesis. For example, as Moshman (2009) points out, even preschool children are rational agents but come to show increasing sophistication with development with respect to metacognitive aspects of rationality: awareness, evaluation and control of inferences, metalogical understanding and epistemic reasoning. These metarational capacities could well flesh out what the authors have in mind in describing phronesis as a metavirtue, with the added advantage that it provides a well-attested theoretical and empirical basis for its development.

Fourth, the authors note that the most crucial test of whether the proposed phronetic model fares better than the neo-Kohlbergian four-component model is empirical and evince some surprise that a neo-Kohlbergian measure has not yet been devised or empirically put to the test. They report continuing work on developing a measure of the four-component phronetic model. But this mistakes the function of meta-models or the work they can be expected to perform. Each component of either four-component model describes diverse operations and processes that make it unlikely of their being captured by a single measure.

\section{Phronesis at the Vertex}

There is still the matter of whether the proposed phronetic model holds advantage over the neo-Kohlbergian four-component model on other grounds, which was the main burden of the target article. The most crucial comparison comes down to the fourth component of either model. Darnell and colleagues argue that the moral agent has no need of performance or implementation skills described by the fourth neo-Kohlbergian component because, for Aristotle, "phronesis presupposes that the agent already wants the good and does not need to force herself to attain it." Instead what is required is for emotions to be infused with reason, which becomes the fourth component of the phronetic model.

But this is implausible. The authors go out of their way to reject what is now commonplace in developmental science, that emotion and reason are inextricably bound at every moment in development. The interdependence of cognition and emotion is vouchsafed also by current neuroscience (Pessoa, 2008) and is assumed by social cognitive models of personality touted earlier. Moreover, the phronesis model comes 
dangerously close to endorsing a discredited pyramidal model that divides the mind into lower and higher levels that run "... up to a vertex that is able to impart order to this hierarchy of functions and, above all, that is able to direct coherently the "noblest functions' that define rational self-consciousness" (De Caro \& Marraffa, 2016, p. 1696). Invariably the lower orders include passions, instincts and emotions, and in the phronetic model also early modeled habits and possibly individual virtues; and at the vertex stands phronesis both to impart reason and to keep an eye on individual virtues. But it does not work that way. As De Caro and Marraffa (2016, p. 1697) point out, there is no higher or lower and no clear demarcation between emotion and reason; both are conventional labels that describe heterogeneous concepts belonging to the "unleveled universe to which all psychological events belong."

\section{Phronesis and Moral Identity}

Moral identity shows up increasingly in various componential models. In the target article moral identity is understood as a kind of blueprint (or else a blueprint that gives shape and substance to moral identity). In Nucci's (2018) model, it is part of the self-system that is in dynamic interaction with the character system. Cohen and colleagues include moral identity as part of a tripartite model of moral character (Cohen \& Morse, 2014; Cohen, Panter, Turan, Morse \& Kim, 2014). This underscores the centrality of the construct for any robust conception of the moral person. Of course, moral identity is not the same as moral character, as Nucci (2018) points out, and the possibility that moral identity could be false (Moshman, 2004), have a dark side (Lapsley, 2016) or be problematic in other ways (Nucci, 2004) is not disputed. But for my money there is not a single other construct that is better associated with a wider swath of moral behavior, and while moral identity has been scored for not having a clear developmental grounding in childhood (Krettenauer \& Hertz, 2015) and for being a "single component" (the target article), there is promising new research on both fronts.

For example, Kingsford and colleagues make a conceptual and empirical case for the emergence of moral identity in middle childhood and show how it covaries with moral emotion (Kingsford, 2018; Kingsford, Hawes \& de Rosnay, 2018). In addition, Hannah, Thompson and Herbst (2018) show that moral identity is a complex construct with several dimensions (and is hardly a "single component"). This literature may pay dividends in sorting out moral identity's role in future work of moral character.

\section{Alternative Accounts of Phronesis and Virtues}

Finally, there is a strong competitor to the phronetic model advanced in the target article. For example, De Caro, Vaccarezza and Niccoli (2018) are sharply critical of the "standard Aristotelian view" of phronesis and reconceptualize practical wisdom as a general or unified form of ethical expertise. They write: "When one is virtuous, what one really possesses is the single virtue of practical wisdom, understood as ethical expertise - the other virtues are descriptive of such virtues in each different moral field" (p. 294). All of the moral excellences are pulled together in the single virtue of wisdom. When we admire someone for being "courageous" what is really ad- 
mired is that one is practically wise ("ethically expert") in a context that involves danger and fear. This account opposes the notion of global traits, insists on a constitutive integration of reason and emotion, addresses the situationist challenge, offers a realistic conception of unity of virtues and moral growth (as extending ethical expertise to an increasing number of domains) and promotes a unified moral agency that is "sensitive to the particularity of the situation's moral requirements" (p. 296). It also has interesting educational implications (train in overall ethical expertise rather than fuss about habituation of several specific virtues).

One attraction of this phronesis-as-ethical-expertise perspective is its possible alignment with recent work that conceptualizes virtues in terms of skills (Stichter, 2018). A second attraction is that the development and cultivation of skills to increasing levels of expertise is something that developmental, cognitive and learning science already understands quite well (e.g., Bransford, Brown \& Cocking, 1999; Ericsson, 2017), and it is a perspective that finds a home in contemporary moral psychology (Narvaez, 2005; Narvaez \& Lapsley, 2005). If phronesis is to be retained as a useful construct, then I suggest looking at the synergy among these literatures for the way forward across the mending wall of moral psychology.

\section{References}

Alfano, M. (2011). Explaining away intuitions about traits: Why virtue ethics seems plausible (even when it isn't). Review of Philosophy and Psychology, 2(1), 121-136. doi:10.1007/s13164-010-0045-9

Annas, J., Narvaez, D. \& Snow, N.E. (Eds.) (2016). Developing the virtues: Integrating perspectives. New York, NY: Oxford University Press.

Arthur, J., Kristjánsson, K., Harrison, T., Sanderse, W., \& Wright, D. (2017). Teaching character and virtue in schools. New York, NY: Routledge.

Bauer, J. J., McAdams, D. P., \& Pals, J. L. (2008). Narrative identity and eudaimonic well-being. Journal of Happiness Studies, 9(1), 81-104. doi:10.1007/s10902-006-9021-6

Bransford J.D., Brown, A.L., \& Cocking, R.R. (Eds.) (1999). How people learn: Brain, mind, experience and school. Washington, DC: National Academy Press.

Caldwell, T. L., Cervone, D., \& Rubin, L. H. (2008). Explaining intra-individual variability in social behavior through ideographic assessment: The case of humor. Journal of Research in Personality, 42(5), 1229-1242. doi:10.1016/j.jrp.2008.03.008

Cantor, N. (1990). From thought to behavior: "Having" and "doing" in the study of personality and cognition. The American Psychologist, 45(6), 735-750. doi:10.1037/0003-066X.45.6.735

Cantor, N., \& Kihlstrom, J.F. (Eds.) (1981). Personality, cognition and social interaction. Hillsdale, NJ: Erlbaum Associates.

Cervone, D. (2004). The architecture of personality. Psychological Review, 111(1), 183-204. doi: 10.1037/0033-295X.111.1.183

Cervone, D. (2005). Personality architecture: Within-person structures and processes. Annual Review of Psychology, 56(1), 423-452. doi:10.1146/annurev.psych.56.091103.070133

Cervone, D., \& Little, B. L. (2015). Personality architecture and dynamics: The new agenda and what's new about it. Personality and Individual Differences, 136, 12-23. doi:10.1016/j.paid.2017.07.001

Cervone, D., \& Shoda, Y. (Eds.) (1999). The coherence of personality: Social-cognitive bases of consistency, variability and organization. New York, NY: Guilford Press.

Cervone, D., \& Tripathi, R. (2009). The moral function of the person as a whole: On moral psychology and personality science. In D. Narvaez \& D. Lapsley (Eds.), Personality, identity and character: Explorations in moral psychology (pp. 30-51). New York, NY: Cambridge University Press. doi:10.1017/ CBO9780511627125.003

Cohen, T. R., \& Morse, L. (2014). Moral character: What it is and what it does. Research in Organizational Behavior, 34, 43-61. doi:10.1016/j.riob.2014.08.003

Cohen, T. R., Panter, A. T., Turan, N., Morse, L., \& Kim, Y. (2014). Moral character in the workplace. Journal of Personality and Social Psychology, 107(5), 943-963. doi:10.1037/a0037245 
De Caro, M., \& Marraffa, M. (2016). Debunking the pyramidal mind: A plea for synergy between reason and emotion. The Journal of Comparative Neurology, 524(8), 1695-1698. doi:10.1002/cne.23870

De Caro, M., Vaccarezza, M.S. \& Niccoli, A. (2018). Phronesis as ethical expertise: Naturalism of secondnature and the unity of virtue. Journal of Value Inquiry, 52, 287-305.

Doris, J. M. (2002). Lack of character: Personality and moral behavior. New York, NY: Cambridge University Press. doi:10.1017/CBO9781139878364

Doris, J., Stich, S., Phillips, J., \& Walmsley, L. (2017). Moral psychology: Empirical approaches. In E. Zalta (Ed.), The Stanford encyclopedia of philosophy (Winter 2017 ed.). Stanford, CA: Stanford University. Retrieved from https://plato.stanford.edu/archives/win2017/entries/moral-psych-emp/

Dunne, J. (1992). Back to the rough ground: "Phronesis" and "techne" in modern philosophy and Aristotle. Notre Dame, IN: University of Notre Dame Press.

Ericsson, K. A. (2017). Expertise and individual differences: The search for the structure and acquisition of experts' superior performance. Wiley Interdisciplinary Reviews: Cognitive Science, 8(1-2), e1382. doi: $10.1002 /$ wcs. 1382

Fairweather, A. \& Alfano, M. (Eds.) (2017). Epistemic situationism. Oxford, UK: Oxford University Press.

Fiske, S.T., \& Taylor, S.E. (Eds.) (2013). Social cognition: From brains to culture (2nd ed.). Thousand Oaks, CA: Sage.

Fleeson, W., \& Jayawickreme, E. (2015). Whole trait theory. Journal of Research in Personality, 56, 82-92. doi:10.1016/j.jrp.2014.10.009

Fleeson, W., Furr, R. M., Jayawickreme, E., Meindl, P., \& Helzer, E. G. (2014). Character: The prospects for a personality-based perspective on morality. Social and Personality Psychology Compass, 8(4), 178191. doi: $10.1111 / \mathrm{spc} 3.12094$

Fowers, B. J. (2012). An Aristotelian framework for the human good. Journal of Theoretical and Philosophical Psychology, 32(1), 10-23. doi:10.1037/a0025820

Hannah, S. T., Thompson, R. L., \& Herbst, K. C. (2018). Moral identity complexity: Situated morality within and across work and social roles. Journal of Management. doi:10.1177/0149206318814166

Higgins, E.T., Herman, C.P., \& Zanna, M.P. (Eds.) (1981). Social cognition: The Ontario symposium. Hillsdale, NJ: Erlbaum.

Hursthouse, R. (1999). On virtue ethics. Oxford, UK: Oxford University Press.

Jayawickreme, E., \& Fleeson, W. (2017). Does whole trait theory work for the virtues? In W. SinnottArmstrong \& C. B. Miller (Eds.), Moral psychology: Virtue and character (Vol. 5, pp. 75-103). Cambridge, MA: MIT Press. doi:10.2307/j.ctt1n2tvzm.9

Jayawickreme, E., Zachary, C. E., \& Fleeson, W. (2019). Whole trait theory: An integrative approach to examining personality structure and process. Personality and Individual Differences, 136, 2-14. doi: 10.1016/j.paid.2018.06.045

Kingsford, J. M. (2018). The emergence of moral identity in middle childhood and the concomitant development of moral shame (Unpublished doctoral dissertation), University of Sydney, Australia.

Kingsford, J. M., Hawes, D. J., \& de Rosnay, M. (2018). The moral self and moral identity: Developmental questions and conceptual challenges. British Journal of Developmental Psychology, 36(4), 652-666. doi: $10.1111 /$ bjdp. 12260

Krettenauer, T., \& Hertz, S. (2015). What develops in moral identities? A critical review. Human Development, 58(3), 137-153. doi:10.1159/000433502

Kristjánsson, K. (2013). Virtues and vices in positive psychology: A philosophical critique. Cambridge, UK: Cambridge University Press. doi:10.1017/CBO9781139177818

Kristjánsson, K. (2015). Aristotelian character education. New York, NY: Routledge. doi:10.4324/ 9781315752747

Lakatos, I. (1978). Falsification and the methodology of scientific research programmes. In J. Worrall \& G. Currie (Eds.), The methodology of scientific research programmes. Imre Lakatos philosophical papers (Vol. 1, pp. 8-101). Cambridge, UK: Cambridge University Press. doi:10.1093/acprof:oso/ 9780190271466.003.0003

Lapsley, D. (2016). Moral self-identity and the social-cognitive theory of virtue. In J. Annas, D. Narvaez, \& N.E. Snow (Eds.), Developing the virtues: Integrating perspectives (pp. 34-68). New York, NY: Oxford University Press. doi:10.1017/CBO9780511621123.003

Lapsley, D., \& Hill, P. (2009). The development of the moral personality. In D. Narvaez \& D. K. Lapsley (Eds.), Personality, identity and character: Explorations in moral psychology (pp. 185-213). Cambridge, UK: Cambridge University Press. doi:10.1017/CBO9780511627125.009

Lapsley, D., \& Narvaez, D. (2004). A social-cognitive view of moral character. In D. Lapsley \& D. Narvaez (Eds.), Moral development, self and identity (pp. 189-212). Mahwah, NJ: Erlbaum. 
Lerner, R. M. (2018). Character development: Four facets of virtues. Child Development Perspectives. doi: $10.1111 /$ cdep. 12315

Marshall, S. P. (1995). Schemas in problem-solving. Cambridge, UK: Cambridge University Press. doi: $10.1017 / \mathrm{CBO} 9780511527890$

Miller, C. B. (2014). Character and moral psychology. Oxford, UK: Oxford University Press. doi:10.1093/ acprof:oso/9780199674367.001.0001

Miller, C.B. (2019). Some philosophical concerns about how the VIA classifies character traits and the VIA-IS measures them. Journal of Positive Psychology. Retrieved from https://doi.org/10.1080/17439 760.2018 .1528377

Mischel, W. (2004). Toward a cognitive science of the person. Annual Review of Psychology, 55, 1-22. doi: 10.1146/annurev.psych.55.042902.130709

Moshman, D. (2009). The development of rationality. In H. Siegel (Ed.), The Oxford handbook of philosophy of education (pp. 145-161). Oxford, UK: Oxford University Press.

Narvaez, D. (2005). The neo-Kohlbergian tradition and beyond: Schemas, expertise and character. In G. Carlo \& C. Pope-Edwards (Eds.), Nebraska symposium on motivation: Vol. 51. Moral motivation through the lifespan (pp. 119-163). Lincoln, NE: University of Nebraska Press.

Narvaez, D., \& Lapsley, D. (2005). The psychological foundations of everyday morality and moral expertise. In D. Lapsley \& F. C. Power (Eds.), Character psychology and character education (pp. 140-165). Notre Dame, IN: University of Notre Dame Press.

Narvaez, D., \& Rest, J. (1995). The four components of acting morally. In W. Kurtines \& J. Gewirtz (Eds.), Moral behavior and moral development: An introduction (pp. 385-400). New York, NY: McGraw-Hill.

Nucci, L. (2004). Reflections on the moral self construct. In D. K. Lapsley \& D. Narvaez (Eds.), Moral development, self and identity (pp. 111-132). Mahwah, NJ: Erlbaum Associates.

Nucci, L. (2017). Character: A multi-faceted developmental system. Journal of Character Education, 13, $1-6$.

Nucci, L. (2018). Character: A developmental system. Child Development Perspectives. doi:10.1111/ cdep. 12313

Overton, W. F. (2015). Process and relational developmental systems. In R.M. Lerner (Editor-in-Chief), \& W.F. Overton \& P.C.M. Molenaar (Eds.), Handbook of child psychology and developmental science: Vol. 1. Theory and method (7th ed., pp. 652-682). Hoboken, NJ: Wiley.

Pessoa, L. (2008). On the relationship between emotion and cognition. Nature Reviews. Neuroscience, 9(2), 148-158. doi:10.1038/nrn2317

Reilly, T. S., \& Narvaez, D. (2018). Character, virtue and science: Linking psychological and philosophical views. Philosophy, Theology and the Sciences, 5, 51-79. doi:10.1628/ptsc-2018-0005

Rest, J., Narvaez, D., Bebeau, M. J., \& Thoma, S. J. (1999). Postconventional moral thinking: A neo-Kohlbergian approach. Mahwah, NJ: Lawrence Erlbaum Associates.

Russell, D. C. (2011). Practical intelligence and the virtues. New York, NY: Oxford University Press.

Scott, W. D., \& Cervone, D. (2016). Social cognitive personality assessment: A case conceptualization procedure and illustration. Cognitive and Behavioral Practice, 23(1), 79-98. doi:10.1016/j.cbpra.2015. 01.003

Shoda, Y., \& Mischel, W. (2000). Reconciling contextualism with core assumptions of personality psychology. European Journal of Personality, 14(5), 407-422. doi:10.1002/1099-0984(200009/10)14: 5407::AID-PER3913.0.CO;2-3

Sinnott-Armstrong, W., \& Miller, C.B. (Eds.) (2017). Moral psychology: Vol. 5. Virtue and character. Cambridge, MA: MIT Press.

Snow, N. (2015). Generativity and flourishing. Journal of Moral Education, 44(3), 263-277. doi: $10.1080 / 03057240.2015 .1043876$

Stichter, M. (2018). The skillfulness of virtue: Improving our moral and epistemic lives. Cambridge, UK: Cambridge University Press. doi.org/10.1017/9781108691970

Tiberius, V. (2015). Moral psychology: A contemporary introduction. New York, NY: Routledge.

Wright, J.C., Warren, M.T., \& Snow, N. (forthcoming). Understanding virtue: Theory and measurement. New York, NY: Oxford University Press. 